\title{
Congenital anomalies among live births in a polluted area. A ten-year retrospective study
}

\author{
Emilio Antonio Luca Gianicolo ${ }^{1 *}$, Antonella Bruni ${ }^{1}$, Enrico Rosati ${ }^{2}$, Saverio Sabina ${ }^{1}$, Roberto Guarino ${ }^{1}$, \\ Gabriella Padolecchia ${ }^{4}$, Carlo Leo ${ }^{4}$, Maria Angela Vigotti ${ }^{3,5}$, Maria Grazia Andreassi ${ }^{3}$ and Giuseppe Latini ${ }^{1,2}$
}

\begin{abstract}
Background: Congenital anomalies and their primary prevention are a crucial public health issue. This work aimed to estimate the prevalence of congenital anomalies in Brindisi, a city in southeastern Italy at high risk of environmental crisis.

Methods: This research concerned newborns up to 28 days of age, born between 2001 and 2010 to mothers resident in Brindisi and discharged with a diagnosis of congenital anomaly. We classified cases according to the coding system adopted by the European Network for the Surveillance of Congenital Anomalies (EUROCAT). Prevalence rates of congenital anomalies in Brindisi were compared with those reported by EUROCAT. Logistic regression models were adapted to evaluate the association between congenital anomalies and municipality of residence of the mother during pregnancy.
\end{abstract}

Results: Out of 8,503 newborns we recorded 194 subjects with congenital anomalies (228.2/10,000 total births), 1.2 times higher than the one reported by the EUROCAT pool of registries. We observed 83 subjects with congenital heart diseases with an excess of $49.1 \%$. Odds Ratios for congenital heart diseases significantly increased for newborns to mothers resident in Brindisi (OR $1.75 \mathrm{Cl} 95 \%$ 1.30-2.35).

Conclusions: Our findings indicated an increased prevalence of Congenital Anomalies (especially congenital heart diseases) in the city of Brindisi. More research is needed in order to analyze the role of factors potentially involved in the causation of congenital anomalies.

Keywords: Congenital anomalies, Hospital discharge data, Surveillance of birth defects, Registers of congenital anomalies

\section{Background}

Congenital anomalies (CAs) and their primary prevention are an important public health issue and both genetic and environmental factors can contribute to their causation [1]. According to Dolk [2], "Environmental factors include any non-genetic factor that increases the risk of a birth defect for the exposed individual. Such factors are nutritional excesses or deficiencies (e.g. folic acid), maternal illness or infection (e.g. diabetes, rubella), drugs taken during pregnancy (e.g. thalidomide), chemical exposure in the workplace or home (e.g., to solvents or pesticides) and radiation (e.g., medical X-ray)."

\footnotetext{
* Correspondence: emilio.gianicolo@ifc.cnr.it

${ }^{1}$ National Research Council, Institute of Clinical Physiology, Campus Ecotekne Building A7, Via per Monteroni, 73100, Lecce, Italy

Full list of author information is available at the end of the article
}

Scientific literature is interested in the association between CAs and the possible role of chemical contaminants [3], and fetuses are thought to be a further subgroup of the population who could be vulnerable to the effects of air pollutants $[4,5]$.

Brindisi is a town in the Apulia region of southeastern Italy and has a population of about 90,000, covering an area of almost $330 \mathrm{~km}^{2}$ with a population density of 271.9 inhabitants per $\mathrm{km}^{2}$. Brindisi is the capital of the homonymous province, which has a population of about 402,800 and covers an area of $1,839 \mathrm{~km}^{2}$ with a population density of 219.2 inhabitants per $\mathrm{km}^{2}$.

Many sources of pollution are located near the urban area: a huge petrochemical plant, chemical, pharmaceutical, metallurgical and manufacturing plants, an incinerator and three power plants, two of which are coal-fired,

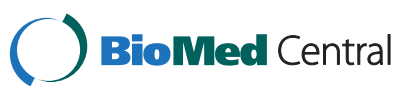


producing around 4,400 Megawatts (Figure 1). Moreover, illegal dumps have been found, and the airport and maritime ports, both located in town, have also increased their activity.

In the 1980s, Brindisi and its surrounding municipalities were identified by the Italian Ministry of Environment as an "area at high risk of environmental crisis" [6] and in 1998 the town was included among the 57 sites of the national program of environmental remediation [7]. Epidemiological studies have revealed several critical situations in terms of increasing rates of mortality and morbidity associated with environmental and occupational exposure to pollutants [8-12]. Recently, an analysis of air quality data carried out for the period 1992-2007 revealed the influence of both the industrial area and the harbor on air pollutant concentration in Brindisi [13]. Very recently, although with imprecision due to broad confidence intervals, standardized mortality ratios for congenital anomalies in all ages were observed to be higher than expected (regional reference) in the period 1995-2001 [14]. The authors suggested a plausible role of environmental exposure and they hypothesized the etiological role of pollutants produced both by the petrochemical plant and by dumps [14].

Given this context and in absence of a CA registry, the aim of this study was to estimate the prevalence of congenital anomalies in Brindisi from hospital discharge data (HDD) among newborns in Brindisi between 2001 and 2010 and to compare them with prevalence rates reported by the European network for the surveillance of congenital anomalies (EUROCAT).

\section{Methods}

This study concerned newborns $0-28$ days of age, born between 2001 and 2010 to mothers resident in Brindisi and discharged with a diagnosis of CA. Data were extracted from the HDD of the local health unit, which is the regional government unit that holds health records for the entire province of Brindisi, including those related to births. HDD included information on cumulative personal files and healthcare records on diagnoses, the main one and up to five for each discharge record,

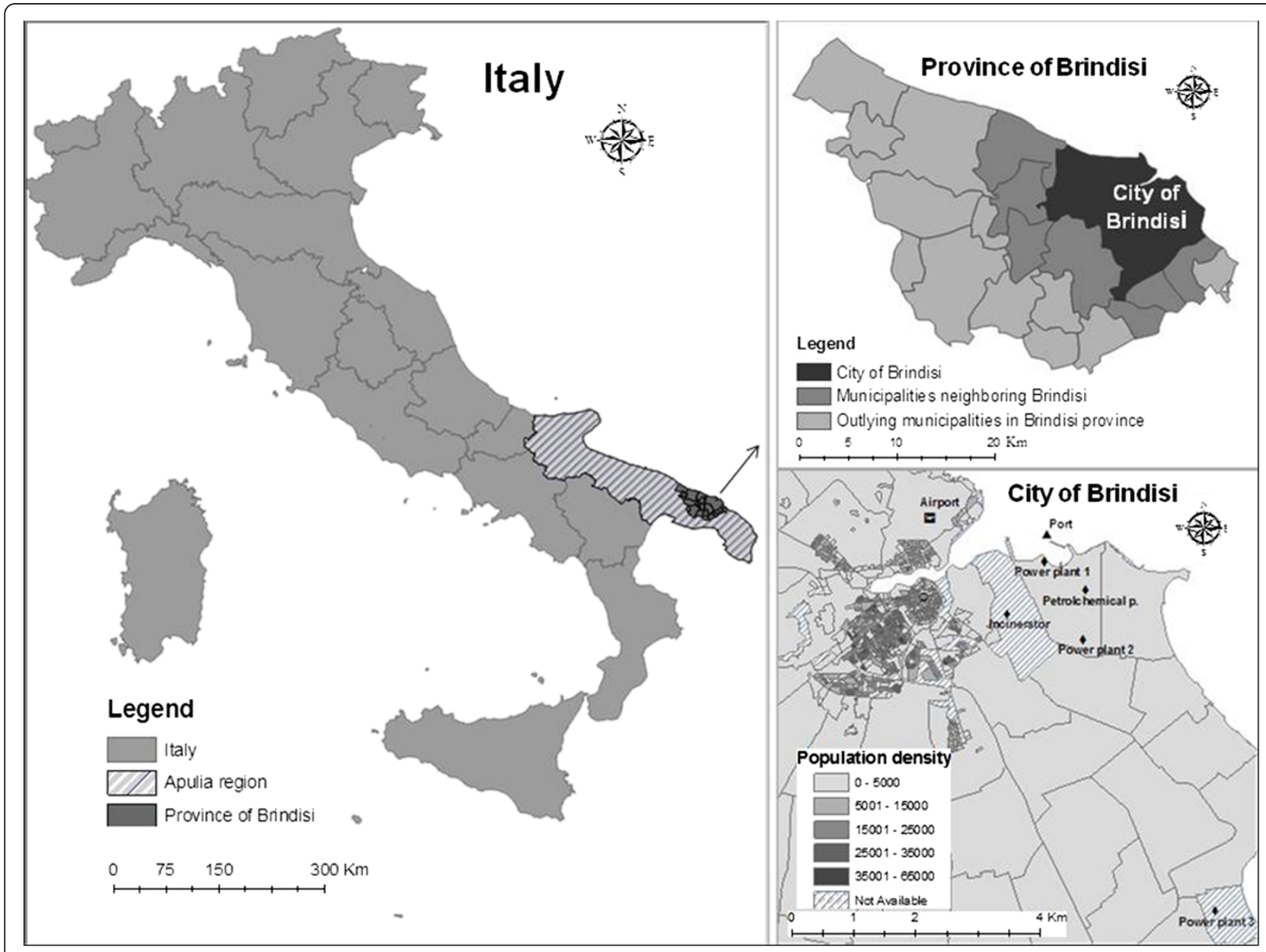

Figure 1 The area of the study: emission sources and population density. 
coded according to the International Classification of Diseases - Clinical Modification, 9th Revision (ICD-9-CM). We considered as cases the newborns with a CA recorded in any of the diagnostic fields. The groups of congenital anomalies analyzed and corresponding ICD-9-CM codes are reported in Table 1.

We classified cases in the following categories: total CAs, congenital heart disease (CHDs) and other CAs according to the coding system adopted by the European Network for the Surveillance of Congenital Anomalies EUROCAT. Subcategories of CHDs with at least five cases were also analyzed.

\section{Table 1 Congenital anomaly subgroups and corresponding ICD-9-CM codes}

\begin{tabular}{|c|c|}
\hline $\begin{array}{l}\text { Congenital anomalies } \\
\text { subgroups }\end{array}$ & ICD9-CM codes \\
\hline Nervous system & $740-742$ \\
\hline Eye & 743 \\
\hline Ear. face and neck & 744 \\
\hline Congenital heart disease & $745-746,747-747.4$ \\
\hline -Common arterial truncus & 745.00 \\
\hline -Transposition of great vessels & 745.10 \\
\hline -Single ventricle & 745.3 \\
\hline - Ventricular septal defect & 745.4 \\
\hline -Atrial septal defect & 745.5 \\
\hline -Atrioventricular septal defect & 745.6 \\
\hline -Tetralogy of Fallot & 745.2 \\
\hline -Tricuspid atresia and stenosis & 746.1 \\
\hline -Ebstein's anomaly & 746.2 \\
\hline -Pulmonary valve atresia & 746.01 \\
\hline -Pulmonary valve stenosis & 746.02 \\
\hline -Aortic valve atresia / stenosis & 746.3 \\
\hline -Hypoplastic left heart & 746.7 \\
\hline -Coarctation of aorta & 747.1 \\
\hline $\begin{array}{l}\text {-Total anomalous pulm venous } \\
\text { return }\end{array}$ & 747.42 \\
\hline Respiratory & 748 \\
\hline Oro-facial clefts & $749.0-749.2$ \\
\hline Digestive system & $750-751,756.6$ \\
\hline Abdominal wall defects & $756.70-756.71,756.79$ \\
\hline Urinary & $753,756.72,752.62$ \\
\hline $\begin{array}{l}\text {-Bladder exstrophy and / or } \\
\text { epispadia }\end{array}$ & $753.5,752.62$ \\
\hline Genital & 752.0-752.4, 752.60, 752.61, 752.7-752.9 \\
\hline -Hypospadia & 752.61 \\
\hline Limb & $754.3-754.8,755$ \\
\hline Musculo-skeletal & $\begin{array}{r}754.0-754.2,756.0-754.5,756.8-756.9, \\
762.80\end{array}$ \\
\hline Chromosomal & 758.0-758.3, 758.5-758.9 \\
\hline Other malformations & $747.5-747.9,757,759.0-759.7$ \\
\hline
\end{tabular}

Registries in EUROCAT register information about newborns and the mothers using different data sources [15]. Registries in EUROCAT use the code system of the British Paediatric Association Classification of Diseases ICD-9-BPA, which is a five-digit extension of the ninth revision of the International Classification of Diseases (ICD-9). Thus, in order to have comparable data set we used the corresponding ICD-9-CM codes.

We adopted EUROCAT exclusion criteria for minor anomalies with less medical, functional or cosmetic importance [16]. We excluded cases with patent ductus arteriosus (PDA) in preterm babies $\left(<37^{\text {th }}\right.$ gestational week) [16]. For this purpose, in order to correctly identify the gestational week (information not recorded on HDD) it was necessary to recover each case-history.

All cases of CA with more than one anomaly were counted only once in the "Total CAs" category.

We calculated observed/expected ratios with $95 \%$ confidence interval (CI 95\%) [17]: expected cases (E) were obtained by multiplying the proportion of newborns with CAs in the pool of EUROCAT registries [18] by the number of live births to mothers resident in Brindisi.

For each category of CAs, we calculated a rate ratio (RR) obtaining by dividing the prevalence ratios observed among males by the prevalence ratio observed among females [19].

We classified CHDs in the following three classes according to their severity defined on the basis of perinatal mortality rates: Severity I (high perinatal mortality); Severity II (medium perinatal mortality); Severity III (low perinatal mortality) [20]. We also classified CHDs according to the presence or absence of an associated chromosomal anomaly [20].

Together with expert neonatologists and a geneticist, we analyzed 994 records extracted from HDD (11.7\% of the total population of newborns) admitted to the local Neonatal Intensive Care Unit (NICU) and registered in an independent and more detailed archive, in order to evaluate the validity of the diagnosis reported in the HDD. Sensitivity, specificity, and positive and negative predictive (PPV and PPN) values were thus calculated in order to estimate validity [21].

For local comparison purposes logistic regression models, adjusted at municipality level for a social economic deprivation index [22] and for maternal average age at delivery, were adapted to evaluate the association between CAs/CHDs and municipality of residence of the mother during pregnancy. For this purpose, municipalities were grouped into three categories: Brindisi, neighboring municipalities and outlying municipalities in Brindisi province.

Statistical analysis was performed using SAS statistical software (SAS Institute Inc, Cary, NC, USA) version 8.2 for Microsoft Windows (Microsoft Corporation, Redmont, WA, USA). 
On May 282010 (reference number 38131), the ethics committee of the Brindisi local health unit approved our research. Research was in compliance with the Helsinki Declaration. Written informed consent from the parents was obtained.

\section{Results}

Table 2 reports the prevalence rates and the ratio of observed/expected number of anomalies based on the pool of EUROCAT registries. Out of 8,503 live births to mothers resident in Brindisi, 194 newborns showed CAs, 83 a CHD. The prevalence rate of total CAs was 228.2/ 10,000 newborns. The expected number of cases was 165.5 and the ratio $\mathrm{O} / \mathrm{E}=117.2(95 \% \mathrm{CI} 101.8-134.9 ; \mathrm{p}<0.05)$ (Table 2). The prevalence rate for the CHDs was 97.6 and the ratio $\mathrm{O} / \mathrm{E}=149.1$ (95\% CI 120.2-184.8; $\mathrm{p}<0.001)$. Excesses were observed for each of the subcategories of CHDs considered, with strong evidence against the null hypothesis for Ventricular Septal Defect (179.6; 95\% CI 133.7241.3; $\mathrm{p}<0.001)$ and Pulmonary Valve Stenosis $(267.6$; 95\% CI 133.4-533.2; $\mathrm{p}<0.01$ ) (Table 2). Observed cases of Other CAs were close to the expected ones (Table 2).

Out of 83 cases with CHD, we observed 9 cases (10.8\%) with medium probability of perinatal mortality (Severity II) and 69 cases (83.1\%) with low probability of perinatal mortality (Severity III). No case with high probability of perinatal mortality was registered. Five cases $(6 \%)$ were not classified because of a poorly specified code. Two cases of CHDs (2.4\%) were associated with a chromosomal anomaly.

CAs were more frequent among males $(R R=1.42$, 95\% CI 1.07-1.89; $\mathrm{p}<0.05$, not shown in table).

Of 8,503 newborns from mother resident in Brindisi, 994 (11.7\%) were admitted to the NICU division and registered in an independent and very detailed archive, which was used for validation purposes. A total of 45 out of 65 met the case definition for one of the major
CAs (Table 3 ) and 24 out of 25 children for CHD (Table 3 ). Therefore, sensitivity was $69.2 \%$ and $96 \%$ respectively. The specificity was in both cases almost $100 \%$. PPV was $73.8 \%$ for all CAs and $85.7 \%$ for CHDs; NPV was $97.9 \%$ and 99.9\% respectively.

In municipalities neighboring Brindisi 8,669 cases of CAs were observed; 17,523 cases were registered in the outlying municipalities in Brindisi province. The prevalence of CAs is more frequent among newborns to mothers resident in the city of Brindisi (Table 4). Odds Ratios for CHDs were significantly higher in the city of Brindisi (OR $=1.85$; 95\% CI: $1.36-2.50)$ then in the outlying municipalities in Brindisi province (Table 5).

\section{Discussion}

Our findings indicated prevalence rate of CAs, and in particular of CHDs, was higher in Brindisi than those reported by the pool of EUROCAT registries and those observed in neighboring municipalities.

For this analysis, 28 days was chosen as maximum age for the diagnosis of CAs; this cut-off might induce a bias comparison since in EUROCAT registries the maximum age for diagnosis has a wide range of variation (1 week to 15 years) [15].

Registries are one of the most accurate approaches in terms of case ascertainment and diagnostic detail, thus assuring reliability in estimating prevalence rates of CAs and a valid base of surveillance systems [23]. Nevertheless, limited resources in birth defect surveillance programs sometimes require the use of electronic health archives - already available and designed for administrative purposes - for surveillance by public health researchers [24].

The HDD archive is increasingly used to estimate the occurrence of a wide range of diseases and more recently also to estimate neonatal morbidity and birth defects [25]. HDD were originally designed for administrative purposes,

Table 2 Newborns with congenital anomalies born to mothers resident in the city of Brindisi and comparison with the pool of EUROCAT registries

\begin{tabular}{|c|c|c|c|c|c|c|c|}
\hline \multirow{2}{*}{$\begin{array}{l}\text { Subgroups of } \\
\text { congenital anomalies }\end{array}$} & \multicolumn{2}{|r|}{ Brindisi } & \multicolumn{4}{|c|}{ Pool of EUROCAT registers } & \multirow[t]{2}{*}{$p^{a}$} \\
\hline & Cases observed & Rates x 10,000 livebirths & Rates x 10,000 livebirths & Expected & $(\mathrm{O} / \mathrm{E}) \times 100$ & $95 \% \mathrm{Cl}$ & \\
\hline All anomalies ${ }^{c}$ & 194 & 228.2 & 194.6 & 165.5 & 117.2 & $101.8-134.9$ & * \\
\hline Congenital heart disease & 83 & 97.6 & 65.4 & 55.7 & 149.1 & $120.2-184.8$ & $* * *$ \\
\hline - Ventricular septal defect & 44 & 51.7 & 28.8 & 24.5 & 179.6 & $133.7-241.3$ & $* * *$ \\
\hline - Atrial septal defect & 17 & 20.0 & 19.9 & 16.9 & 100.7 & 62.5-161.8 & \\
\hline - Pulmonary valve stenosis & 8 & 9.4 & 3.5 & 3.0 & 267.6 & $133.4-533.2$ & $* *$ \\
\hline Other congenital anomalies & 122 & 143.5 & 153.9 & 130.9 & 93.2 & 78.1-111.3 & \\
\hline
\end{tabular}

$\mathrm{a} * \mathrm{P}<0.05$; ${ }^{* * \mathrm{P}}<0.01$; ${ }^{* *} \mathrm{P}<0.001$; ${ }^{* * *} \mathrm{P}<0.0001$.

${ }^{\mathrm{b}}$ Pool of Italian registries.

"Cases of CAs with more than one anomaly were counted only once in "All anomalies" category. Numbers do not add up because of newborns with more than one CA.

Absolute values, rates for 10,000 live births, $\mathrm{O} / \mathrm{E}$ ratios and $\mathrm{Cl} 95 \%$.

City of Brindisi, 2001-2010. 
Table 3 Validity of hospital discharge data for identifying infants with CAs and CHDs

\begin{tabular}{|c|c|c|c|c|c|}
\hline \multirow{2}{*}{$\begin{array}{l}\text { Cases identified through } \\
\text { Hospital Discharge Data }\end{array}$} & \multicolumn{5}{|c|}{ Gold Standard (NICU) } \\
\hline & Yes & $\%$ & No & $\%$ & Total \\
\hline \multicolumn{6}{|l|}{ ALL CONGENITAL ANOMALIES } \\
\hline Yes & 45 & 73.8 & 16 & 26.2 & 61 \\
\hline No & 20 & 2.1 & 913 & 97.9 & 933 \\
\hline Total & 65 & 6.5 & 929 & 93.5 & 994 \\
\hline \multirow[t]{2}{*}{ Sensitivity } & \multicolumn{2}{|l|}{$69.2 \%$} & \multicolumn{2}{|c|}{$\begin{array}{l}\text { Positive } \\
\text { predictive value }\end{array}$} & $73.8 \%$ \\
\hline & \multicolumn{2}{|c|}{$\begin{array}{l}95 \% \text { Cl (57.3 - } \\
79.5)\end{array}$} & & \multicolumn{2}{|c|}{$\begin{array}{l}95 \% \text { Cl (61.7 - } \\
83.6)\end{array}$} \\
\hline \multirow[t]{2}{*}{ Specificity } & \multicolumn{2}{|l|}{$98.3 \%$} & \multicolumn{2}{|c|}{$\begin{array}{l}\text { Negative } \\
\text { predictive value }\end{array}$} & $97.9 \%$ \\
\hline & \multicolumn{2}{|c|}{$\begin{array}{l}95 \% \mathrm{Cl}(61.7- \\
83.6)\end{array}$} & & \multicolumn{2}{|c|}{$\begin{array}{l}95 \% \text { Cl (96.8 - } \\
98.7)\end{array}$} \\
\hline \multicolumn{6}{|l|}{ CONGENITAL HEART DISEASE } \\
\hline Yes & 24 & 85.7 & 4 & 14.3 & 28 \\
\hline No & 1 & 0.1 & 965 & 99.9 & 966 \\
\hline Total & 25 & 2.5 & 969 & 97.5 & 994 \\
\hline \multirow[t]{2}{*}{ Sensitivity } & \multicolumn{2}{|l|}{$96.0 \%$} & \multicolumn{2}{|c|}{$\begin{array}{l}\text { Positive } \\
\text { predictive value }\end{array}$} & $85.7 \%$ \\
\hline & \multicolumn{2}{|c|}{$\begin{array}{l}95 \% \mathrm{Cl}(81.8- \\
99.8)\end{array}$} & & \multicolumn{2}{|c|}{$\begin{array}{l}95 \% \text { Cl (69.1 - } \\
95.3)\end{array}$} \\
\hline \multirow[t]{2}{*}{ Specificity } & \multicolumn{2}{|l|}{$99.6 \%$} & \multicolumn{2}{|c|}{$\begin{array}{l}\text { Negative } \\
\text { predictive value }\end{array}$} & $99.9 \%$ \\
\hline & \multicolumn{2}{|c|}{$\begin{array}{l}95 \% \text { Cl (99.2 - } \\
99.9)\end{array}$} & & \multicolumn{2}{|c|}{$\begin{array}{l}95 \% \mathrm{Cl}(99.5- \\
100.0)\end{array}$} \\
\hline
\end{tabular}

City of Brindisi, at single NICU facility, 2001-2010.

but they can be exploited as an abundant, inexpensive source of epidemiological information on large patient populations [25]. Although issues have been raised regarding geographic variability of archive quality and completeness [26], HDD are considered an important source of information to estimate diseases such as CAs [27].

Together with expert neonatologists and a geneticist, we observed a subset of cases admitted to the NICU and registered in an independent and more detailed archive, in order to evaluate the validity of the diagnosis reported in the HDD. High frequencies of diagnoses correctly recorded was observed. Nevertheless, the validity study was conducted only on a single hospital [21], so the validity of data in other Italian areas must be further demonstrated.

This study could not have identified cases of infants with a CA born at home. Nevertheless, according to the National Institute of Statistics [28], in Italy the percentage of births not occurring in public or private hospitals is $0.1 \%$ and it is mainly concentrated in the northern part of Italy. Therefore, this phenomenon can be assumed to be rare in the investigated area and it would not have had any effect on the estimated prevalence of CAs.

Our results on sex differences confirm those reported in literature regarding an increased risk among male newborns [29].

It has recently been suggested that environmental risk factors might play an important role in the etiology of CHD [30-32].

Environmental pollutants of concern for health impact include a wide range of airborne contaminants such as nitrogen dioxide $\left(\mathrm{NO}_{2}\right)$, sulfur dioxide $\left(\mathrm{SO}_{2}\right)$, carbon monoxide $(\mathrm{CO})$, ozone $\left(\mathrm{O}_{3}\right)$; particulate matter $(\mathrm{PM})$ and heavy metals (specifically cadmium, lead, mercury, chromium and arsenic), and organic compounds, specifically dioxins and furans, polychlorinated biphenyls (PCBs), and polycyclic aromatic hydrocarbons (PAHs). Their main sources are traffic, industrial emissions and hazardous waste sites. In recent years, population-based and case-control studies have reported an increased risk of congenital anomalies in polluted areas, especially for selected congenital heart defects [30,33-39].

Some important limitations must be considered when interpreting the results of this study.

First, environmental data at the individual or ecological level were not available.

Secondly, we were not able to adjust our analysis for potential confounding factors that are known or suspected to increase the risk of congenital anomalies, such as maternal diabetes, smoking, parental occupation and social determinants, because they were unavailable in the HDD archives [40,41].

Thirdly, data covered live births only. In estimating the prevalence of CAs in a population, stillbirths and pregnancy terminations should be taken into account. Many fetuses die in utero and technological advances in

Table 4 Newborns and cases of CAs according to the residence of the mother during pregnancy

\begin{tabular}{|c|c|c|c|c|c|}
\hline \multirow{2}{*}{$\begin{array}{l}\text { Residence of the mother during } \\
\text { pregnancy }\end{array}$} & \multirow{2}{*}{$\begin{array}{r}\text { All } \\
\text { newborns }\end{array}$} & \multicolumn{2}{|c|}{ All congenital anomalies } & \multicolumn{2}{|c|}{ Cases with CHDs ${ }^{\mathrm{a}}$} \\
\hline & & Absolute values & Cases $\times 10,000$ & Absolute values & Cases $\times 10,000$ \\
\hline City of Brindisi & 8,503 & 193 & 227.0 & 82 & 96.4 \\
\hline Municipalities neighboring Brindisi & 8,669 & 157 & 181.1 & 57 & 65.8 \\
\hline Outlying municipalities in Brindisi province & 17,523 & 360 & 205.4 & 99 & 56.5 \\
\hline
\end{tabular}

${ }^{a}$ Cases with diagnosis of PDA were excluded due to the impossibility of identifying the exact gestational week for newborns to mothers resident in municipalities other than Brindisi.

Absolute values and rates for 10,000 live births.

Province of Brindisi, 2001-2010. 
Table 5 Crude and adjusted ORs (95\% CI) for CAs and CHDs residence of the mother during pregnancy

\begin{tabular}{|c|c|c|c|c|c|c|}
\hline \multirow[t]{2}{*}{ Residence of the mother during pregnancy } & \multicolumn{3}{|c|}{ Unadjusted } & \multicolumn{3}{|c|}{ Adjusted $^{b}$} \\
\hline & OR & $\mathrm{Cl} 95 \%$ & $\mathrm{P}^{\mathrm{a}}$ & OR & $\mathrm{Cl} 95 \%$ & $\mathbf{P}^{\mathbf{a}}$ \\
\hline \multicolumn{7}{|l|}{ ALL CONGENITAL ANOMALIES } \\
\hline Outlying municipalities in Brindisi province (reference) & 1 & & & 1 & & \\
\hline City of Brindisi & 1.13 & 0.95-1.35 & & 1.13 & $0.94-1.35$ & \\
\hline Municipalities neighbour to Brindisi & 0.90 & 0.74-1.09 & & 0.85 & $0.69-1.05$ & \\
\hline \multicolumn{7}{|l|}{ CONGENITAL HEART DISEASE } \\
\hline Outlying municipalities in Brindisi province (reference) & 1 & & & 1 & & \\
\hline City of Brindisi & 1.75 & $1.30-2.35$ & $* * *$ & 1.85 & $1.36-2.50$ & $* * * *$ \\
\hline Municipalities neighbour to Brindisi & 1.19 & $0.86-1.66$ & & 1.08 & $0.75-1.55$ & \\
\hline
\end{tabular}

$\mathrm{a} * \mathrm{P}<0.05 ;{ }^{* *} \mathrm{P}<0.01 ;{ }^{* * *} \mathrm{P}<0.001 ;{ }^{* * * \mathrm{P}}<0.0001$

${ }^{\mathrm{b}}$ Models are adjusted at municipality level for a social economic deprivation index and for average maternal age at delivery.

Province of Brindisi, 2001-2010.

diagnosis provide a growing possibility of reaching termination of pregnancy. This is a very important issue that needs to be addressed in estimating prevalence of CAs but could not be tackled in the present study. However, although the frequency of voluntary abortion in Italy in the years 2006-2007 ( $230 \times 1,000$ newborns) was lower than the European one (244) [42], in Apulia the frequency was much higher (304) than in the other Italian regions [43]. Thus, the higher CA rates observed in Brindisi might not be biased by pregnancy terminations. However, this aspect together with the study of incidents of CAs among stillbirths should be further investigated.

\section{Conclusions}

Our data showed the validity of HDD in estimating the prevalence of CAs in the city of Brindisi. Furthermore, an increased prevalence of CAs (especially CHDs) in the city of Brindisi, known to be an area at high risk of environmental crisis, was observed. More research in terms of etiological studies is needed, in order to analyze the role of different risk factors in the possible causation of CAs. In this work we did not have any personal or ecological exposure data. Therefore, it was impossible to infer about the possible role of pollution. Nevertheless, our working group is now focusing on exposure data and on the correlation between environmental data and health data. This will be the aim of our next paper.

Results from this kind of study ought to reduce this burden through identifying the best strategies for primary prevention.

\section{Abbreviations}

CAs: Congenital Anomalies; HDD: Hospital Discharge Data; EUROCAT: European Surveillance of Congenital Anomalies; ICD-9CM: International Classification of Diseases - Clinical Modification, $9^{\text {th }}$ Revision; CHDs: Congenital Heart Diseases; PDA: Patent Ductus Arteriosus; NICU: Neonatal Intensive Care Unit; PPV: Positive Predictive Value; PPN: Negative Predictive Value; Cl: Confidence Interval; E: Expected; O: Observed; RR: Rate Ratio; $\mathrm{NO}_{2}$ : Nitrogen Dioxide; $\mathrm{SO}_{2}$ : Sulfur Dioxide;
CO: Carbon Monoxide; $\mathrm{O}_{3}$ : Ozone; PM: Particulate Matter;

PCBs: Polychlorinated Biphenyls; PAHs: Polycyclic Aromatic Hydrocarbons.

Competing interests

The authors declare no competing interests.

\section{Authors' contributions}

EALG, analyzed data, reviewed the literature and was the main contributor to writing the manuscript. $A B$, managed the newborns data, the record linkage and contributed to writing the manuscript. ER, contributed in analysing each case-history and validating the diagnosis of congenital anomalies. SS and RG were responsible for data recovery from NICU data set and contributed to writing the manuscript. GP and LC provided Hospital Discharge Data. MAV and MGA reviewed the literature and the final manuscript. GL, was Senior Physician and contributed to writing the manuscript. All authors read and approved the final manuscript.

\section{Acknowledgements}

The National Research Council, Institute of Clinical Physiology of Lecce conducted this study in cooperation with the Division of Neonatology, Perrino Hospital of Brindisi. This work was partially supported by the Italian Association for the Study of Malformations - Associazione Italiana per lo Studio delle Malformazioni (ASM Onlus).

We wish to thank Alison Frank for helping revise and edit the English. We acknowledge Mr. Cosimo Saracino for helping recover patients' case-history and acknowledge professor Eugenio Picano for useful discussions.

\section{Author details}

${ }^{1}$ National Research Council, Institute of Clinical Physiology, Campus Ecotekne Building A7, Via per Monteroni, 73100, Lecce, Italy. Division of Neonatology, Perrino Hospital, Brindisi, Italy. ${ }^{3}$ National Research Council, Institute of Clinical Physiology, Pisa, Italy. ${ }^{4}$ Local Health Unit, Brindisi, Italy. ${ }^{5}$ University of Pisa, Pisa, Italy.

Received: 11 April 2012 Accepted: 18 December 2012

Published: 27 December 2012

\section{References}

1. Dolk H, Loane M, Garne E: The prevalence of congenital anomalies in Europe. Adv Exp Med Biol 2010, 686:349-364.

2. Dolk H: Epidemiological evidence regarding environmental causes of congenital anomalies: interpretational issues. In EUROCAT special report: A Review of Environmental Risk Factors for Congenital Anomalies. Co Antrim Northern Ireland: University of Ulster Newtownabbey; 2004:30-47.

3. Dolk H: Epidemiological approaches to identifying environmental causes of birth defects. Am J Med Genet C Semin Med Genet 2004, 125C(1):4-11.

4. Pope CA 3rd: Epidemiology of fine particulate air pollution and human health: biologic mechanisms and who's at risk? Environ Health Perspect 2000, 108(Suppl. 4):713-723. 
5. Perera FP, Jedrychowski W, Rauh V, Whyatt R: Molecular epidemiologic research on the effects of environmental pollutants on fetus. Environ Health Perspect 1999, 107(suppl):451-460.

6. Law of the Italian Parliament of 8 July 1986, n.349: "Istituzione del Ministero dell'ambiente e norme in materia di danno ambientale", published on Supplemento ordinario n.59 alla Gazzetta Ufficiale. n. 162, 15 July 1986; 1986.

7. Law of the Italian Parliament of 9 December 1998, n. 426: "Nuovi interventi in campo ambientale", published on Gazzetta Ufficiale n. 291, 14 december 1998; 1998.

8. Martuzzi M, Mitis F, Biggeri A, Terracini B, Bertollini R: Environment and health status of the population in areas with high risk of environmental crisis in Italy. Epidemiol Prev 2002, 26(6 Suppl):1-53.

9. Belli S, Benedetti M, Comba P, Lagravinese D, Martucci V, Martuzzi M, Morleo D, Trinca S, Viviano G: Case-control study on cancer risk associated to residence in the neighbourhood of a petrochemical plant. Eur J Epidemiol 2004, 19(1):49-54.

10. Gianicolo EA, Serinelli M, Vigotti MA, Portaluri M: Mortality in the municipalities of Brindisi Province, 1981-2001. Epidemiol Prev 2008, 32(1):49-57.

11. Serinelli M, Gianicolo EA, Cervino M, Mangia C, Portaluri M, Vigotti MA: Acute effects of air pollution in Brindisi (Italy): a case-crossover analysis. Epidemiol Prev 2010, 34(3):100-107.

12. Calculli C, Pollice A, Serinelli M: Spatial analysis of the risk of multiple cancers in relation to a petrochemical plant. Environmetrics 2011 23:175-182.

13. Mangia C, Bruni A, Cervino M, Gianicolo EAL: Sixteen-year air quality data analysis of a high environmental risk area in Southern Italy. Environ Monit Assess 2011, 183(1-4):555-570.

14. Pirastu R, Zona A, Ancona C, Bruno C, Fano V, Fazzo L, lavarone I, Minichilli F, Mitis F, Pasetto R, Comba P: SENTIERI project - mortality study of residents in Italian polluted sites: RESULTS. Epidemiol Prev 2011, 35(5-6):59-61. Suppl. 4.

15. Greenlees R, Neville A, Addor MC, Amar E, Arriola L, Bakker M, Barisic I, Boyd PA, Calzolari E, Doray B, Draper E, Vollset SE, Garne E, Gatt M, Haeusler M, Kallen K, Khoshnood B, Latos-Bielenska A, Martinez-Frias ML, Materna-Kiryluk A, Dias CM, McDonnell B, Mullaney C, Nelen V, O'Mahony M, Pierini A Queisser-Luft A, Randrianaivo-Ranjatoélina H, Rankin J, Rissmann A, Ritvanen A, Salvador J, Sipek A, Tucker D, Verellen-Dumoulin C, Wellesley D, Wertelecki W: Paper 6: EUROCAT member registries: organization and activities. Birth Defects Res A Clin Mol Teratol 2011, 91(Suppl. 1):S51-S100.

16. EUROCAT (European Surveillance of Congenital Anomalies): EUROCAT Guide 1.3 and reference documents. Instructions for the Registration and Surveillance of Congenital Anomalies; 2005. [http://www.eurocat-network.eu/content/ EUROCAT-guide-1.3.pdf.] Accessed 30th November 2011.

17. Rothman KJ, Greenland S, Lash TL: Modern Epidemiology. 3rd edition. Philadelphia, PA: Lippincott Williams \& Wilkins; 2008.

18. EUROCAT (European Surveillance of Congenital Anomalies): Access prevalence data. Prevalence tables; 2011. [http://www.eurocat-network.eu/ accessprevalencedata/prevalencetables] Accessed 30th November 2011.

19. Lary JM, Paulozzi $\amalg$ : Sex differences in the prevalence of human birth defects: a population-based study. Teratology 2001, 64(5):237-251.

20. Dolk H, Loane M, Garne E: European surveillance of congenital anomalies (EUROCAT) working group. congenital heart defects in Europe: prevalence and perinatal mortality, 2000 to 2005. Circulation 2011, 123(8):841-849.

21. Frohnert BK, Lussky RC, Alms MA, Mendelsohn NJ, Symonik DM, Falken MC Validity of hospital discharge data for identifying infants with cardiac defects. J Perinatol 2005, 25:737-742.

22. Caranci N, Biggeri A, Grisotto L, Pacelli B, Spadea T, Costa G: The Italian deprivation index at census block level: definition, description and association with general mortality. Epidemiol Prev 2010, 34(4):167-176.

23. Lechat MF, Dolk H: Registries of congenital anomalies: EUROCAT. Environ Health Perspect 1993, 101(Suppl 2):153-157.

24. Wang Y, Cross PK, Druschel CM: Hospital discharge data: can it serve as the sole source of case ascertainment for population-based birth defects surveillance programs? J Publ Health Manag Pract 2010, 16(3):245-251.

25. Baldi I, Vicari P, Di Cuonzo D, Zanetti R, Pagano E, Rosato R, Sacerdote C, Segnan N, Merletti F, Ciccone G: A high positive predictive value algorithm using hospital administrative data identified incident cancer cases. J Clin Epidemiol 2008, 61(4):373-379.

26. Simonato L, Baldi I, Balzi D, Barchielli A, Battistella G, Canova C, Cesaroni G, Corrao G, Collini F, Conti S, Costa G, Demaria M, Fornari C, Faustini A, Galassi
C, Gnavi R, Inio A, Madotto F, Milgliore E, Minelli G, Pellizzari M, Protti M, Romanelli A, Russo A, Saugo M, Tancioni V, Tessari R, Vianello A, Vigotti MA: Objectives, tools and methods for an epidemiological use of electronic health archives in various areas of Italy. Epidemiol Prev 2008 32(3 Suppl):5-14.

27. ISTAT: Frequencies of congenital malformation diagnosis. Statistic information system on disability; 2006. [www.disabilitaincifre.it/descrizioni/Malformazioni. pdf]. Accessed 30th November 2011.

28. ISTAT: National survey on Health conditions and recourse to health services 2004-2005; 2010. [http://www.istat.it/it/archivio/7740]. Accessed 15th October 2012

29. Øyen N, Poulsen G, Boyd HA, Wohlfahrt J, Jensen PK, Melbye M: Recurrence of congenital heart defects in families. Circulation 2009, 120:295-301.

30. Ritz B, Yu F, Fruin S, Chapa G, Shaw GM, Harris JA: Ambient air pollution and risk of birth defects in Southern California. Am J Epidemio/ 2002, 55:17-25.

31. Gianicolo EA, Cresci M, Ait-Ali L, Foffa I, Andreassi MG: Smoking and congenital heart disease: the epidemiological and biological link. Curr Pharm Des 2010, 16(23):2572-2577.

32. Cresci M, Foffa I, Ait-Ali L, Pulignani S, Gianicolo EAL, Botto N, Picano E, Andreassi MG: Maternal and paternal environmental risk factors, metabolizing GSTM1 and GSTT1 polymorphisms, and congenital heart disease. Am J Cardio/ 2011, 108(11):1625-1631

33. Dolk $\mathrm{H}$, Vrijheid $\mathrm{M}$ : The impact of environmental pollution on congenital anomalies. Br Med Bull 2003, 68:25-45.

34. Gilboa SM, Mendola P, Olshan AF, Langlois PH, Savitz DA, Loomis D, Herring $\mathrm{AH}$, Fixler DE: Relation between ambient air quality and selected birth defects, seven county study, Texas, 1997-2000. Am J Epidemiol 2005, 162:238-252.

35. Hansen CA, Barnett AG, Jalaludin BB, Morgan GG: Ambient air pollution and birth defects in Brisbane, Australia. PLoS One. 2009, 4(4):e5408.

36. Rankin J, Chadwick T, Natarajan M, Howel D, Pearce MS, Pless-Mulloli T: Maternal exposure to ambient air pollution and risk of congenital anomalies. Environ Res 2009, 109:181-187.

37. Strickland MJ, Klein M, Correa A, Reller MD, Mahle WT, Riehle-Colarusso SJ, Botto LD, Flanders WD, Mulholland JA, Siffel C, Marcus M, Tolbert PE: Ambient air pollution and cardiovascular malformations in Atlanta, Georgia, 1986-2003. Am J Epidemiol 2009, 169:1004-1014.

38. Dolk H, Armstrong K, Vrijheid M, Lachowycz K, Rankin J, Abramsky L, Boyd PA, Wellesley D: Ambient air pollution and risk of congenital anomalies in England, 1991-1999. Occup Environ Med 2010, 67:223-227.

39. Dadvand P, Rankin J, Rushton S, Pless-Mulloli T: Ambient air pollution and congenital heart disease: a register-based study. Environ Res 2011, 111(3):435-441.

40. Morales-Suárez-Varela MM, Bille C, Christensen K, Olsen J: Smoking habits, nicotine use, and congenital malformations. Obstet Gynecol 2006, 107(1):51-57.

41. Varela MM, Nohr EA, Llopis-González A, Andersen AN, Olsen J: Sociooccupational status and congenital anomalies. Eur J Publ Health 2009, 19(2):161-167.

42. World Health Organization (WHO) Regional Office for Europe: European health for all database (HFA-DB) 2011; 2011. Available: [http://data.euro.who. int/hfadb/]. Accessed 30th November 2011.

43. Italian Ministry of Health. Ministry of health report on the social protection of motherhood and voluntary termination of pregnancy (low 194/78) Italian Ministry of Health: Ministry of health report on the social protection of motherhood and voluntary termination of pregnancy (low 194/78); 2008. Available: [http://www.salute.gov.it/imgs/C_17_pubblicazioni_804_allegato. pdf]. Accessed 30th November 2011.

doi:10.1186/1471-2393-12-165

Cite this article as: Gianicolo et al:: Congenital anomalies among live births in a polluted area. A ten-year retrospective study. BMC Pregnancy and Childbirth 2012 12:165. 